\title{
Marlene Yurgel LABORATÓRIO DE INFORMATIZAÇÃO DE ACERVO (LABARQ)
}

Ao solicitar mudança de regime de dedicação à pesquisa em 1990 na FAUUSP, perseguia uma preocupação constante em minhas atividades como docente: qual a abordagem para o ensino da arquitetura na virada do século 20 para o 21?

Exercendo a atividade de professora desde 1965, em escolas de segundo grau, e na FAU a partir de 1972, tratei sempre o ensino como forma contínua de aprendizado. Como elaborar conceitos abstratos de forma compreensível, ligados ao mundo que vemos, ouvimos, pensamos e vivemos?

A consciência sobre o mundo é formada por conceitos os quais nos acompanham desde que nascemos, por gerações e gerações, de transferência oral para entender e aprender todos os padrões que cada cultura impõe. Da ética à estética.

Com a finalidade de entender com maior profundidade o ensino da arquitetura e o exercício dessa profissão em suas variações, dediquei-me a examinar o universo profissional dos arquitetos diplomados pela FAUUSP, examinando suas atividades e sua relação com os currículos, para encontrar um denominador comum. Ouvi também a opinião desses arquitetos sobre a pertinência de sua formação e o exercício de suas ocupações no trabalho. Examinei o longo período de 1952 até 2002, contemplando 50 anos de história desta Escola.

Já em 1992, os primeiros resultados das enquetes apontaram uma direção para as ações voltadas aos novos horizontes do novo milênio para o ensino. A Tecnologia de Informática ( $\mathrm{TI}$ ) precisava ser introduzida. Outra necessidade apontava para a disponibilidade dos trabalhos realizados por arquitetos; além dos antigos slides, tornava-se fundamental apresentar e dispor de projetos e da maneira como foram elaborados para o contato mais próximo como objeto de seu trabalho.

Para compreender os conceitos que a consciência tornou onipresentes padrões para a arquitetura, torna-se essencial examinar as razões desses padrões na história, para romper ou confirmar raciocínios tradicionais que não acompanham o desenvolvimento do conhecimento sobre o universo. Foram essas as preocupações que nortearam a criação do Laboratório de Informatização de Acervo (LabArq), do Departamento de História e Estética do Projeto. Os estudos e 
pesquisas foram sintonizados aos assuntos que estavam no bojo da criação do LabArq: A digitalização de desenhos e documentos para a obtenção de imagens que se aproximassem do original e ficassem claramente visíveis quando apresentados em classe aos alunos. Como fazer com que uma linha dos traços do desenho, transformada por impulso elétrico em pixel (que é um quadrado) fosse organizada para ter a melhor acuidade em relação ao traço, à letra e à cor? Desenhos, documentos e fotografias de tamanhos distintos, grandes e pequenos, em comparação com os dispositivos que permitiam transformá-los em novas imagens visíveis por intermédio de microcomputadores, foram desafios para estudos intermináveis e um conhecimento a ser desbravado. Acompanha também esse processo o armazenamento das imagens por intermédio de suportes ainda em expansão e pouco confiáveis no tempo de uso.

O estudo de TI para o ensino da história da arquitetura voltou-se, igualmente, para examinar situações de restauração de edifícios, novas possibilidades, com técnicas complexas auxiliando a compreensão das construções do passado, e, eventualmente, do presente.

Uma estadia na Universidade de Aachem - Rheinisch Westfaelische Techische Hochschule-Fakultät 2 Architektur - em um programa Capes/DDAD, permitiu um contato com o desenvolvimento de aplicativos de informática utilizados no ensino da arquitetura, com resultados que tornou possível a clara compreensão de um novo instrumento para o projeto. Foi fundamental, em 1994, conhecer esses trabalhos em razão do descaso com que era tratado, aqui na Escola, esse assunto. Até mesmo podemos dizer que "era contra-indicado" para os arquitetos aqui diplomados. "Coisas do demo", as quais serviam para padronizar os projetos.

Em que pese a opinião de meus colegas, continuei a investir no conhecimento do assunto, ao longo dos anos, procurando um objeto claro para aplicação de estudos e pesquisas em torno da TI, que permitisse oferecer, por intermédio da universidade, uma formação inacessível aos alunos, por se tratar de assunto dispensável.

Esse objeto primeiro pôde ser avaliado por uma assessoria realizada pelo LabArq para a Ferrovia Paulista SA - Fepasa - sobre equipamento de informática, uma plataforma de trabalho IBM no valor de U\$1,000,000.00. Para poder opinar sobre isso, é necessário conhecer o objetivo da aquisição, caso contrário são grandes as probabilidades de cometer-se enganos. Ao conhecer 0 destino do uso do equipamento, mensurar o tamanho e valor do patrimônio imobiliário da ferrovia, em vias de ser privatizada, sugeri a compra de microcomputador, com preço muito menor e também a maneira de usá-lo. Resultou daí um projeto piloto de $150 \mathrm{~km}$, realizado pela equipe do LabArq, no qual procedíamos de maneira distinta para a mensuração dos imóveis, criando tipologias por porte e uso com processo de medição de áreas, planímetro eletrônico, até a introdução do geoprocessamento, quando as áreas podem ser medidas por aplicativo.

Tentei uma parceria com professores da Escola Politécnica, que somente aconteceu no segundo trabalho, com o professor José Alberto Quintanilha, continuando até hoje, quando há necessidade e disponibilidade, sendo nosso assessor. 


\section{Iि Atlas da USP}

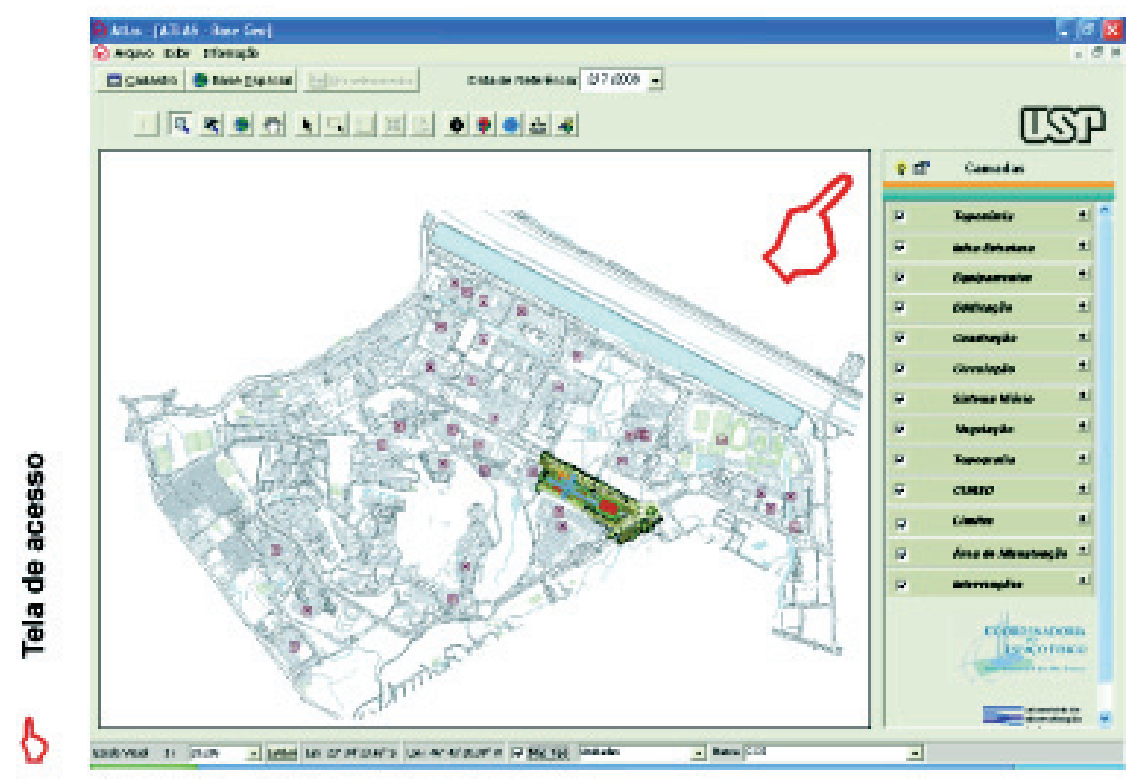

is
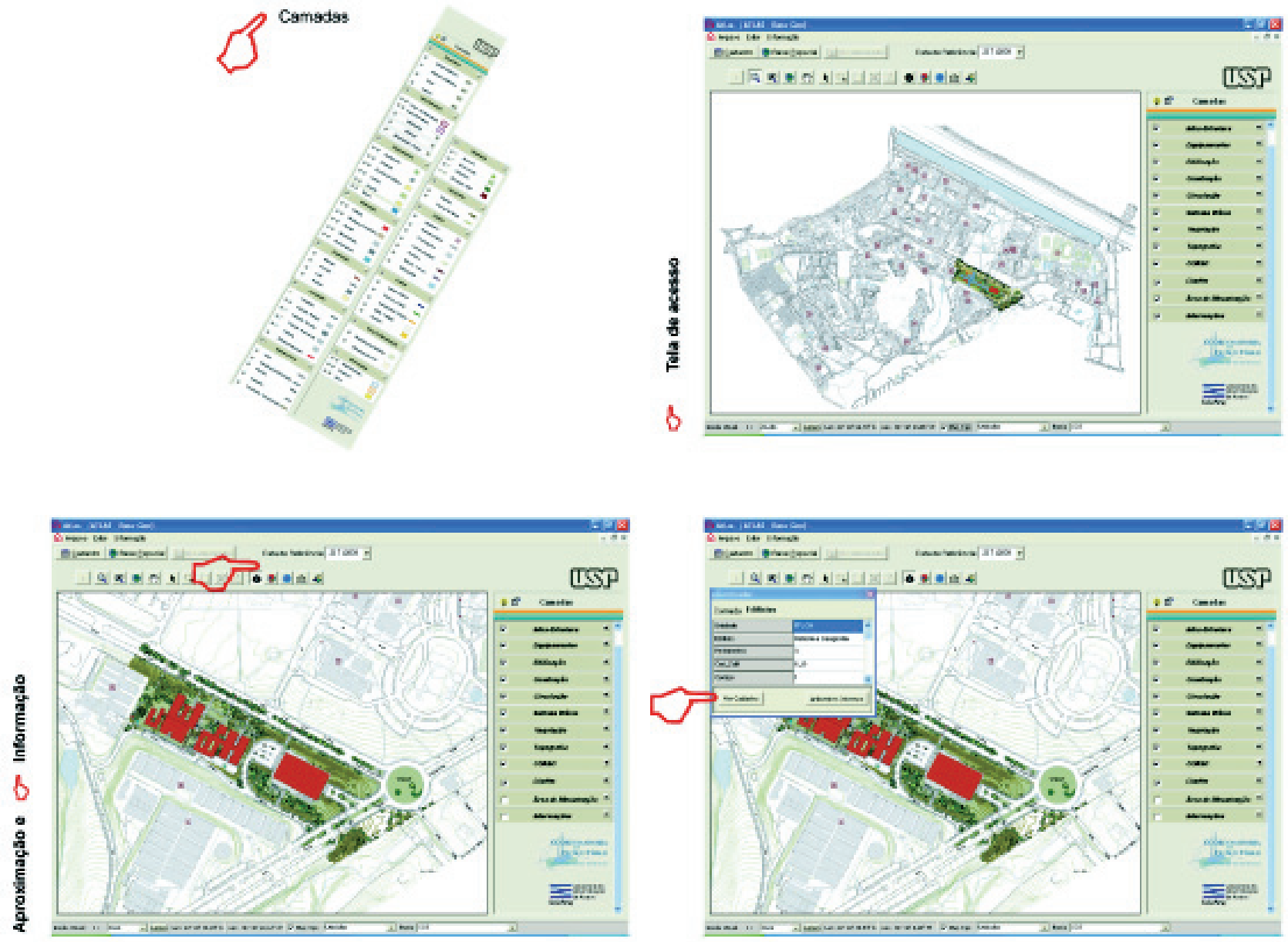

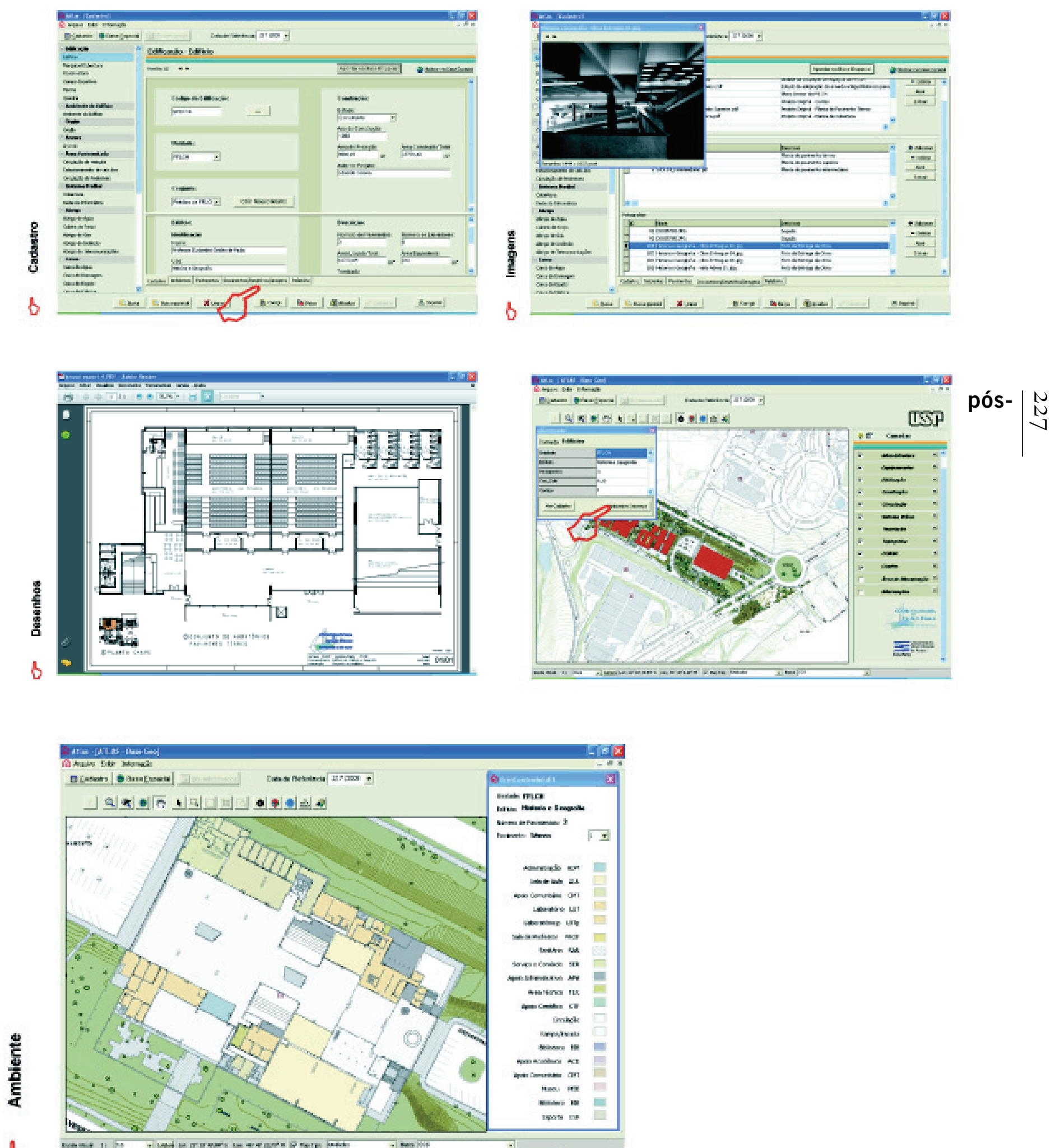
A continuidade do trabalho foi a inserção em aplicativo de geoprocessamento de $1.000 \mathrm{~km}$ de imóveis e da ferrovia em áreas urbanizadas no estado de São Paulo.

Para esse trabalho, iniciava-se uma metodologia de tratar o patrimônio, incluindo a digitalização de originais de desenhos dos trilhos, da faixa de domínio e da projeção dos imóveis, a vetorização das imagens resultantes e transformações em coordenadas para o aplicativo de GIS (Sistema de Informações Geográficas).

Com a colaboração da professora Nice Lecoq Müller, fizemos um esboço de livro - Viagem onírica pelo município de São Paulo - em que tratávamos a história de São Paulo por intermédio de seus caminhos. Os caminhos das águas, os caminhos dos índios, os caminhos para o mar e os outros caminhos. A história desenhada na ocupação do território, por meio das perspectivas que fossem geradas por um aplicativo de GIS e permitissem a visualização das dificuldades da geografia e de seus acessos aos lugares ocupados. Era, então, um sonho, porque os instrumentos dos quais dispúnhamos e as novas tecnologias eram rudimentares. Contamos com um grande levantamento, textos e mapas em três dimensões. Inconcluso.

Procurei apoio de empresas que comercializavam aplicativos de informática para projetos, para uso de arquitetos e engenheiros dispostos a investir em estudar a compatibilidade de seus aplicativos com as normas brasileiras, e a avaliação de desempenho e novas aplicações.

Foram assim estudados:

Módulo Topológico - Hochtief do Brasil S/A

CADdy - CADdy GhK

Restituição por fotografia - USBEK - WENINGER

Nesse período, foi possível oferecer, por intermédio desses apoios, cerca de 30 bolsas de iniciação científica, mestrado e doutorado, sempre um rumo perseguido por mim, o da formação dos estudantes na busca da atualização constante em seus estudos no mundo contemporâneo.

Com a Universidade de Taubaté, desenvolvemos um estudo de recomposição de programa para uma antiga fábrica de tecidos, usando técnicas de restituição precisa por meio de fotografia. Na Inglaterra, trabalhos dessa natureza são denominados arqueologia industrial.

A apresentação do trabalho realizado para a Fepasa, por iniciativa de sua diretoria, em algumas empresas do governo, resultou na solicitação de outros sistemas, permitindo contínuo desenvolvimento e melhoria da criação de aplicativos na área de acervos.

A Companhia Paulista de Trens Metropolitana, CPTM, criada com a privatização da Fepasa, herdou o sistema de operação dos trens, os imóveis e alguns problemas. 0 diretor financeiro, ao assumir o cargo, encontrou como patrimônio da empresa 50 linhas telefônicas, que, na ocasião, tinham um certo valor pecuniário. O responsável por todo o patrimônio da CPTM travou uma batalha de longos meses para contratar o LabArq, visando criar um Sistema de Gerenciamento Patrimonial.

Esse trabalho foi realizado com estudantes de graduação e pós-graduação. Foi necessário levantar todos os documentos, inclusive em cartórios. Digitalizar 
plantas e fichas. Vetorizar trilhos, faixa de domínio, edificações, estações de todas as naturezas, arruamentos, muros e tudo o que servisse de referência para o sistema ser ágil e encontrar o que o acervo contemplava.

Aqui foi possível introduzir um banco de dados visando atender às buscas para o usuário do sistema tornar o trabalho incomparavelmente mais rápido em relação aos processos e desenhos. Estava tudo à mão, ou melhor, no computador. Objeto que causava estranheza em nossos colegas de ensino, medo em funcionários de repartições porque poderiam causar demissões. Ao contrário da CPTM, os funcionários acompanharam todo o processo da criação do sistema e foram treinados ao longo do trabalho, ensinando-nos o que é uma ferrovia.

Novamente, tivemos de apresentar o trabalho em vários lugares por causa do ineditismo do sistema. Muitas visitas foram feitas ao LabArq para conhecê-lo, inclusive funcionários do BIRD, resultando em indicação posterior à criação de outro sistema.

Com a professora Marta Dora Grostein, a qual realizou uma pesquisa sobre os estacionamentos e outros equipamentos no centro de São Paulo, fizemos um mapa georreferenciado que transformamos em desenho para impressão de um folheto à Associação Viva o Centro. Criamos uma versão do Sistema de Gerenciamento para a Ferrovia do Rio de Janeiro, mais complexo porque foram introduzidas informações mais completas, com grande número de elementos da via permanente - trilhos, travessões, aparelhos de mudança de via, entre outros, bem como equipamentos sobre os trilhos, inclusive o sistema de comunicação e eletrificação, postes, etc. O patrimônio que incluiu desde locomotivas e vagões, imóveis, até bens de pequeno porte como mesas, cadeiras, etc. Processos de buscas e impressões de relatórios compreendem o rol das funcionalidades do Sistema do Patrimônio -Sispat. Com esse projeto, o professor Marcelo Eduardo Giacaglia passou a integrar comigo a responsabilidade da coordenação do LabArq. Esse é um sistema georrefenciado, com um banco de dados temporal, informações registradas nas datas de ocorrência dos fatos, além das datas de alimentação no banco, e possíveis de serem encontradas nessas circunstâncias.

Utilizando a tecnologia de geoprocessamento de manipulação de imagens digitais, ensaiamos um instrumento para avaliação de área tombada pelo patrimônio histórico, o caso de Caraguatatuba. Com informações colhidas nos textos das legislações e imagens sobre mapas do município levantados pelo IPT, foi possível criar uma forma palatável de mostrar todas as possibilidades de inferências para os projetos a serem elaborados no município.

$\mathrm{Na}$ oportunidade em que cerca de 400 mapas antigos da coleção do Banco Santos foram dados como guarda provisória à USP, o Instituto de Estudos Brasileiros, IEB, catalogou-os e incluiu-os em seu acervo. Em um projeto conjunto do IEB, FAU e FFLCH, junto da Finep, foi possível adquirir equipamento para a digitalização desses mapas, quando criamos um banco de dados para inserção das imagens, uma vez que se pretendia disponibilizar esse acervo via Internet, principalmente por estudantes do segundo grau. O piloto que elaboramos ficou sem retorno por falta de cuidados da direção. Em elaboração, encontra-se um trabalho que é banco de dados do acervo de projetos do professor Vilanova Artigas. 


\section{BRASILIANA USP}

$\frac{230}{\text { in }}$
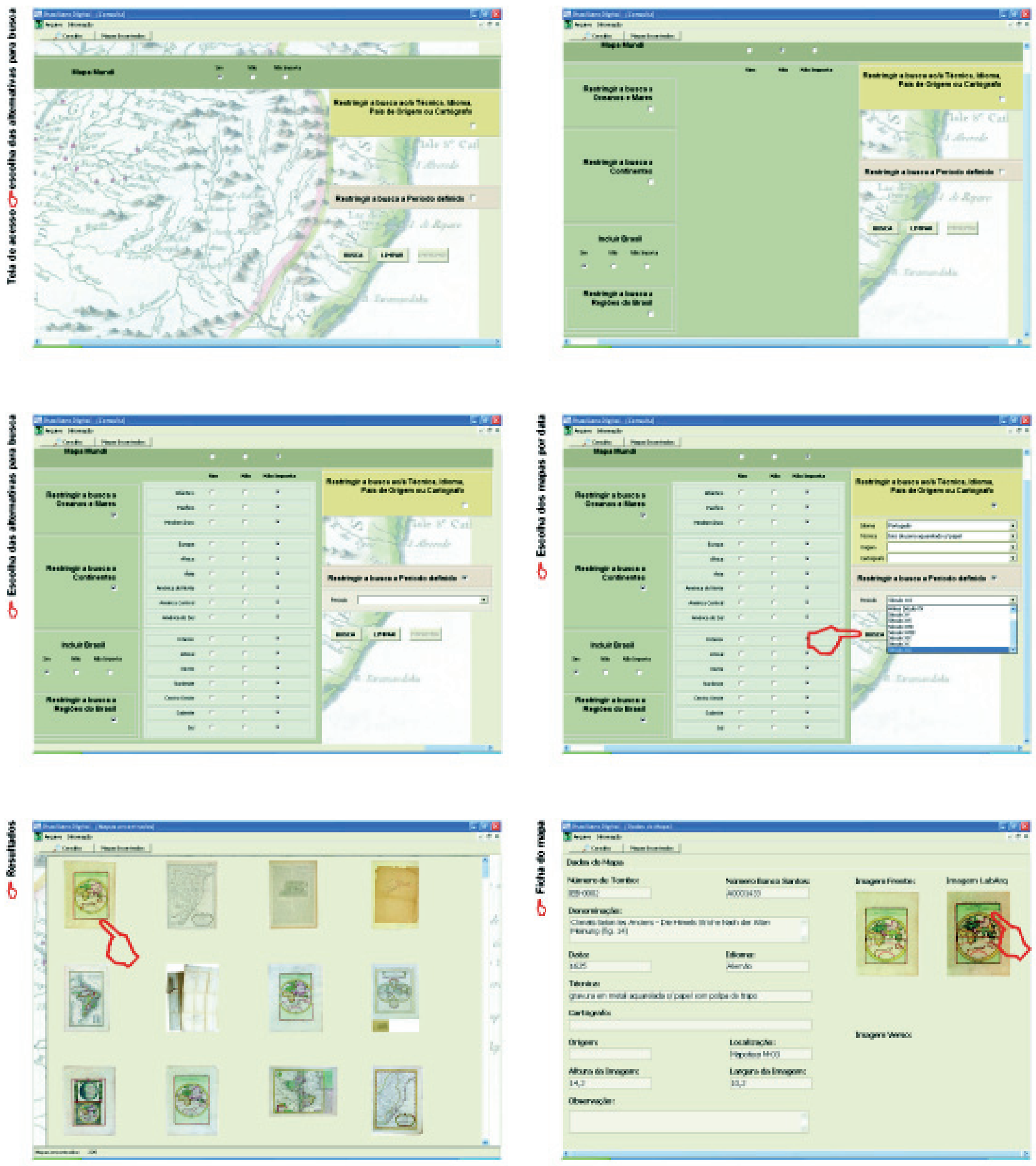

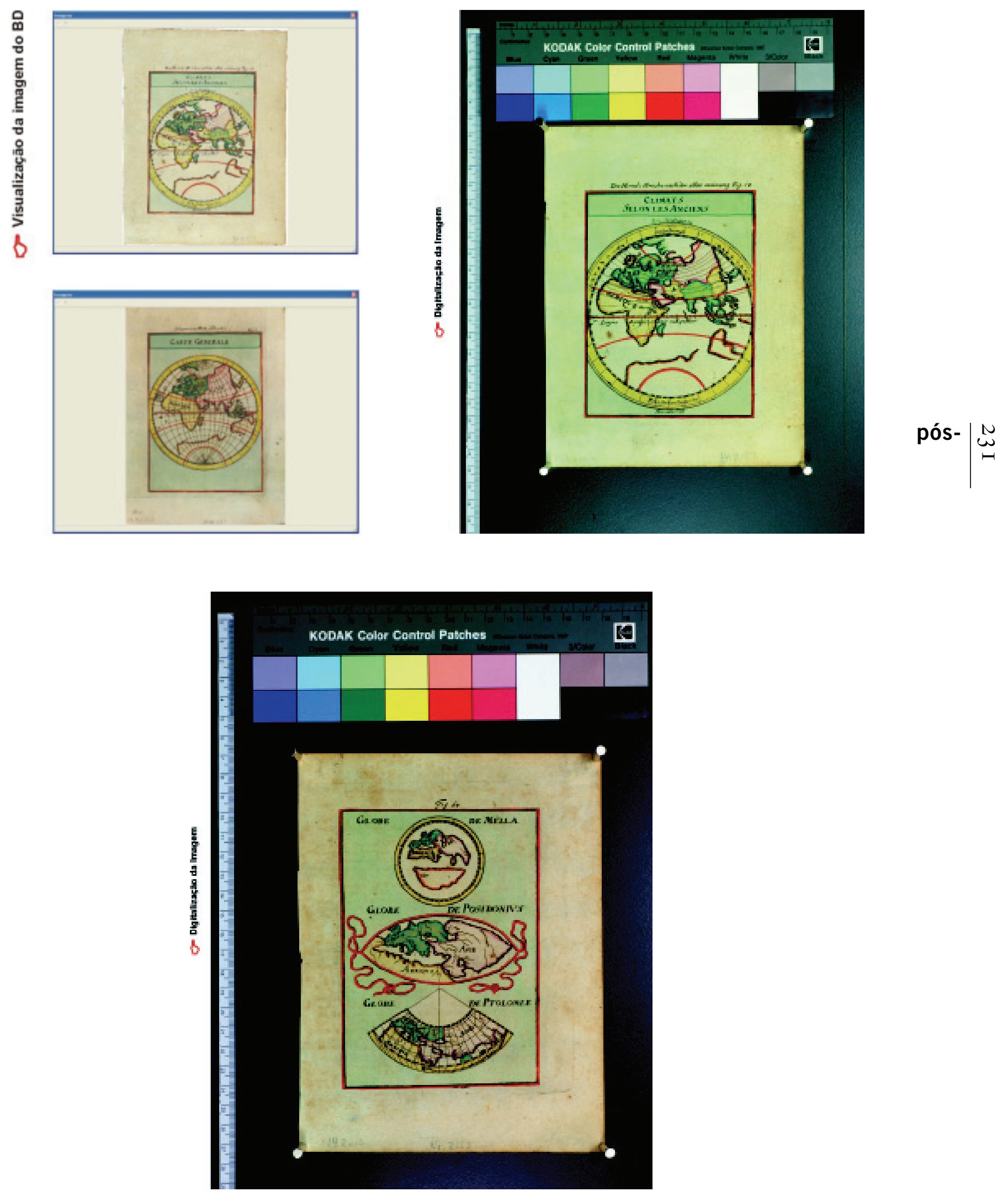

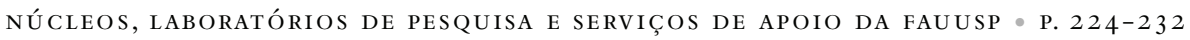


Com a Coordenadoria dos Espaços Físicos da USP (Coesf) desenvolvemos o ATLAS, um piloto para o sistema de gestão dos espaços, inicialmente abrangendo as edificações da FFCLH, no qual podemos examinar as áreas externas e sua infra-estrutura, e as áreas internas de cada edifício com os usos de seus ambientes. Tal sistema, a exemplo do Sispat, desenvolvido para a ferrovia de subúrbio de passageiros do Rio de Janeiro, consiste em um banco de dados georreferenciados, temporal e dos aplicativos de acesso, desenvolvidos segundo as necessidades dos usuários.

A possibilidade de concessão de bolsas aos alunos foi transformada pelas fundações da USP em estágios, que, ao longo desses anos, somam mais de 130, remunerados.

O professor Carlos Augusto Mattei Faggin integrará, a partir de abril de 2008, a coordenação do LabArq.

\author{
Docentes \\ Marlene Yurgel - Coordenadora \\ Carlos Augusto Mattei Faggin \\ Marcelo Eduardo Giacaglia \\ Pesquisadores \\ Anderson Valtriani Siqueira \\ Amarilis Montagnolle \\ Camila de Souza Silva \\ Elenice Souza Lima Teixeira \\ Eunice Barbosa \\ Fábio Gallo Júnior \\ Felipe Rodrigues Venâncio \\ Letícia Bressane \\ Marco Aurélio Grenier Granzotto \\ Milena Costa Gomes \\ Pedro Piccino Alasmar \\ Ricardo Arendt Stieber Couto \\ Ricardo de Lorenzi Kambara \\ Telma Carolina Mendes
}

\title{
Marlene Yurgel
}

Professora titular do Departamento de História e Estética do Projeto, professora orientadora do curso de pós-graduação e coordenadora do Laboratório de Informatização de Acervo da FAUUSP-LabArq.

e-mail: myurgel@usp.b 